\title{
Revista Chilena de Infectología accede a Index Medicus/MEDLINE
}

\author{
Revista Chilena de Infectología has acceded Index Medicus/MEDLINE
}

Agosto 2003-noviembre 2004: 14 meses en que calladamente el Comité Editorial esperó el veredicto favorable del Literature Selection Technical Review Committee (LSTRC) de la National Library of Medicine (NLM) de E.U.A, pocas semanas antes de completar el volumen 21.

Ingresar al registro Index Medicus/MEDLINE de NLM -incluye 4.571 publicaciones a enero del 2005-, ser parte de una institución que data de 1879 y que iniciara la indización de literatura médica periódica en 1971 bajo la sigla MEDLARS, representa un compromiso a nuestro Comité Editorial para mantener los estándares formales que hemos logrado y superar día a día su calidad científica, y su gravitación como tribuna para la especialidad de Infectología.

Con anterioridad, otras publicaciones chilenas del área bio-médica fueron incorporadas a Index Medicus ${ }^{1,2}$. Nuestro "decano" y referente nacional, Revista Médica de Chile fue indizada por la NLM a partir de 1965 y otras que le imitaron, fueron lamentablemente perdiendo este estándar con el paso del tiempo. La última publicación científica nacional en el área que alcanzara esta distinción, antes de nuestro logro, fue Revista Chilena de Historia Natural en el año 1983.

En desconocimiento de las bondades exhibidas por Revista Chilena de Infectología que fueran convincentes para el LSTRC, en nuestra intimidad estimamos que los siguientes factores han sido determinantes:

- Estabilidad del Comité Editorial, condición que indudablemente ha favorecido ir cumpliendo la tarea trazada por nuestro primer Editor y actual Editor Emérito, Guillermo Acuña, de aspirar a la indización internacional: primero en LILACS, luego en el Programa Scielo (Scientific Electronic Library Online), LATINDEX (que contempla títulos provenientes de la Península Ibérica), todos impulsados por BIREME, y ahora en Index Medicus/MEDLINE.

- Política de difundir la revista dentro y fuera del país, llegando incluso a un centenar de especialistas hispano-parlantes en Latino América, España y E.U.A., en bibliotecas universitarias y en hospitales del sistema público de salud chileno, a estudiantes de postgrado y pregrado en cada una de las actividades de extensión organizados por el Directorio de la Sociedad y, en forma testimonial por nuestros socios en el ejercicio diario de nuestra especialidad y en la interacción con colegas de otras especialidades y con estudiantes de medicina en las distintas universidades. La confección de un formato en disco compacto a partir del año volumen 17 (año 2000) ha sido una manera "amable" de llegar a los médicos más jóvenes y de enviar la revista al exterior.

- La politica propuesta por el Comité Editorial y apoyada por el Directorio, de permitir el acceso "libre de costo" al texto completo de la revista al lector interesado sin fines comerciales, y que culminara al ser incorporada al Programa Scielo.cl comandado por CONICYT en Chile.

- La ausencia de otras publicaciones periódicas en la subespecialidad de Infectología en español, que representen a Latinoamérica y con alta divulgación y fácil acceso a sus contenidos.

- El respaldo académico otorgado por una sociedad científica, en este caso la Sociedad Chilena de Infectología. 
Estar en Index Medicus/MEDLINE, a partir de marzo 2005, es una invitación a los autores nacionales y latinoamericanos a publicar en Revista Chilena de Infectología y abre las puertas a crecer en calidad y frecuencia. En este número de la revista, S.H. Vermund y G. Acuña ${ }^{1,2}$ enuncian la trascendencia que hoy en día están adquiriendo las revistas regionales de especialidad y subespecialidad, gracias a la red electrónica mundial, y cuáles debieran ser los pasos futuros en la difusión del saber científico. Allí quedan trazadas ideas para el desarrollo internacional de nuestra publicación.

Es el momento de agradecer las buenas influencias:

A Revista Médica de Chile como ejemplo digno de ser imitado y a su actual Editor, Humberto Reyes $B$, por sus sabios consejos.

A CONICYT, a través de su Programa Scielo.cl, por el respaldo y capacitación entregados a este Editor.

A Sten Vermund, quien ha sido un promotor del desarrollo de revistas regionales en el área médica y cuya opinión fue determinante en el seno de la Sociedad Americana de Enfermedades Infecciosas (Infectious Diseases Society of America- IDSA) para avalar nuestra postulación ante la NLM, de él y de IDSA debemos estar muy reconocidos.

Estamos en antecedentes que diversas sociedades científicas chilenas aspiran a obtener esta ansiada indización, el Comité Editorial de Revista Chilena de Infectología espera compartir con ellas, dentro de poco, los estándares que hoy nosotros hemos alcanzado.

José Cofré Guerra

Editor

\section{Bibliografía}

1.- Vermund S H, Acuña G. Regional journals in medicine and public health: A look to the future upon the indexing of the Revista Chilena de Infectología. Rev Chil Infect 2005; 22: 10-14.
2.- Vermund S H, Acuña G. Revistas regionales de medicina y salud pública: Una mirada al futuro apropósito de la indización de Revista Chilena de Infectología. Rev Chil Infect 2005; 22: 15-19. 